\title{
Exocrine Pancreatic Cancer pNX TNM
}

\section{Finding v8}

National Cancer Institute

\section{Source}

National Cancer Institute. Exocrine Pancreatic Cancer pNX TNM Finding v8. NCI

Thesaurus. Code C134897.

Exocrine pancreatic cancer in which the regional lymph nodes cannot be assessed. (from AJCC 8th Ed.) 